American Journal of Pharmaceutical Education 2017; 81 (3) Article 52.

\title{
RESEARCH
}

\section{Evaluation of a Longitudinal Advanced Pharmacy Practice Experience}

\author{
Jorie A. Frasiolas, PharmD, ${ }^{a}$ Kelly Wright, PharmD, ${ }^{b}$ Amy L. Dzierba, PharmD ${ }^{c}$ \\ ${ }^{a}$ NewYork-Presbyterian Hospital, New York, New York \\ ${ }^{\mathrm{b}}$ Boston Medical Center, Boston, Massachusetts \\ ${ }^{c}$ NewYork-Presbyterian Hospital/Columbia University Irving Medical Center, New York, New York \\ Submitted November 16, 2015; accepted May 29, 2016; published April 2017.
}

Objective. To describe satisfaction and career path of students who participated in the longitudinal advanced pharmacy practice experience (APPE).

Methods. A 3-part survey was administered to students enrolled between January 1, 2010, and December 31, 2013. The sections of the survey evaluated respondents' baseline characteristics, satisfaction, and career path.

Results. Majority of the respondents had a GPA above 3.0 (91\%), pharmacy school honors (84\%), work experience in retail $(16 \%)$ or multiple pharmacy sites $(38 \%)$, and were members of at least one professional organization (76\%). Sixty-nine percent reported that the program exceeded their expectations. Strengths included practice site consistency, rotation diversity, preceptors, presentations, and collaboration with health care professionals. Students gained approximately 76 hours of additional clinical experience, compared to if they completed rotations at individual sites. After graduation, more than half of the respondents accepted a pharmacy practice residency $(67 \%)$.

Conclusion. The results of this study support the need for APPE programs that prepare students to deliver advanced patient care, while providing them with professional development.

Keywords: advanced pharmacy practice experience, longitudinal advanced pharmacy practice experience, longitudinal rotation experience, experiential training, pharmacy practice experience

\section{INTRODUCTION}

As part of an accredited Doctor of Pharmacy curriculum, students are required to complete at least 1440 hours or 36 weeks of advanced pharmacy practice experiences (APPE). Students are placed in various practice settings where they focus on providing direct patient care to diverse patient populations as a member of a multidisciplinary team. Although the number of schools of pharmacy continues to expand, site availability remains stagnant due to financial constraints and competition from introductory pharmacy practice experiences (IPPE). ${ }^{1}$ Additionally, schools prefer rotation sites that balance the quantity and variety of rotations offered, while maintaining a high quality experience. ${ }^{2}$ Furthermore, scheduling rotations is challenging due to preceptor availability, challenges of preceptor development, and student rotation preferences. To address these barriers, academic medical centers and schools of pharmacy have developed programs in which students complete multiple rotations at a single site. In addition to orientation, students

Corresponding Author: Jorie Frasiolas, NewYork-

Presbyterian Hospital, 622 West 168th St., Room VCB, New

York, NY 10032. Tel: 212-305-6529. E-mail:

joriefrasiolas@gmail.com have reported that it takes approximately 8 hours to learn a new computer system and 3 hours to become familiar with each new institution. ${ }^{4}$ Other suggested benefits of a longitudinal approach are increased student involvement in longitudinal projects and research, enhanced professional relationships, and increased interest in post-graduate residency training. ${ }^{3-4}$

In 2007, NewYork-Presbyterian Hospital (NYP) collaborated with St. John's University College of Pharmacy and Health Sciences (SJU) to provide fifth-year pharmacy students with a longitudinal rotation experience. The goal of the program is to provide a comprehensive, acute care learning experience in an academic medical center for highly motivated students who are considering a career in hospital pharmacy. By minimizing orientation time, students have the opportunity to focus on direct patient care activities and critical evaluation of medication therapy. The students are also exposed to the pharmacy residency program and diverse student learning experiences including journal club, case presentation, medication use evaluations and research. This may help the students determine whether they want to pursue a career in hospital pharmacy.

Each year, students are recruited by NYP preceptors at a student rotation fair held at SJU. Additionally, 


\section{American Journal of Pharmaceutical Education 2017; 81 (3) Article 52.}

a formal presentation is delivered to fourth year pharmacy students that describes the longitudinal program, including rotation structure, required presentations and other educational activities. Student applications, which include a letter of intent, curriculum vitae, and pharmacy school transcripts, undergo internal review by an admissions committee composed of NYP preceptors and SJU faculty. Approximately 18 students out of an average of approximately 250 students apply annually, of whom a maximum of 14-16 are selected. At the time of the survey, those who were accepted into the NYP-SJU program completed five, 4-week rotations at NYP, including general hospital, internal medicine and three elective rotations, including but not limited to critical care, solid organ transplant, pediatrics, and oncology. The remainder of their APPE experiences are completed at other practice sites as determined by the School of Pharmacy. The rotations are assigned based upon student preference and preceptor availability. All students spend the first day of their first rotation in orientation, which includes security and health clearance, Health Insurance Portability and Accountability Act (HIPAA) training, review of select policy and procedures, and an introduction to the electronic medical record and other electronic resources (eg, paging system). In addition to clinical rotations, students participate in required journal club and case presentations, which are presented weekly at student common hour. They also have the opportunity to perform research, which may be presented as posters at professional meetings, such as the American Society of Health-System Pharmacists Midyear Clinical Meeting. Additionally, students are exposed to the pharmacy residency program by attending resident journal clubs and case conferences as well as resident led pharmacy grand rounds. Finally, student seminars, which were initiated in January 2012, are 1hour didactic lectures that are led by clinical and operational pharmacists every other week with the goal of improving clinical and professional development. Topics include, but are not limited to, curriculum vitae development, midyear preparation, literature evaluation, anticoagulation, antimicrobials, pain management, and interview skills.

Although several academic medical centers and schools of pharmacy use similar longitudinal models, published literature is limited especially as it relates to the students' perspectives and career choices immediately post-graduation. The objective of this study was to describe the characteristics of students who applied and were selected for the NYP-SJU longitudinal program, their satisfaction with the program, and their chosen career path immediately after graduation.

\section{METHODS}

A 3-part survey developed by the investigators was administered to students who were enrolled in the NYP-SJU longitudinal program between January 1, 2010, and December 31,2013 . The first section was facilitated by a member of the Student Advisory Committee using a paper survey during a face-to-face meeting. Baseline characteristics including age, pharmacy school grade point average, previous education, honors awarded, work experience, professional memberships, and leadership positions within professional pharmacy organizations were self-reported. After completion of assigned clinical rotations, a 10-item anonymous survey was distributed via email in order to evaluate student satisfaction with the NYP-SJU longitudinal program. Strengths and weaknesses of the program were also assessed and were categorized into broader groups including practice site, rotation experiences, preceptors, and student common hour. A final e-mail survey was used to determine career path immediately following graduation from SJU. Up to two reminder e-mails were sent to non-responders of the second and third surveys. No incentives were offered for participation in any section of the survey. The study was approved by the Columbia University Institutional Review Board and all students provided written informed consent.

Descriptive statistics were used to analyze data using Microsoft Excel (Microsoft Corporation, Redmond, WA). Continuous variables were expressed as median (interquartile range). Categorical variables were reported as percentages of total number of students analyzed.

\section{RESULTS}

Of the $53 \mathrm{SJU}$ students enrolled in the NYP longitudinal program between January 1, 2010 and December 31, 2013, 47 consented to participate in the 3-part survey. Forty-six students completed the baseline characteristics survey, with a response rate of $98 \%$. Data from one student were excluded from analysis due to failure to complete the longitudinal program. Baseline demographics for the remaining 45 students are presented in Table 1. Two-thirds of the respondents were female, with a median age of 23 years. None of the students received a degree prior to enrolling in pharmacy school. The majority of students had a pharmacy school GPA above 3.0 (91\%), received honors in high school $(84 \%)$ and/or received honors in pharmacy school (84\%). Of the 45 respondents, $44(98 \%)$ had pharmacy-related work experience, most commonly in retail $(44 \%)$ or multiple pharmacy sites $(38 \%)$ for at least two years (64\%). Approximately three quarters of respondents were members of at least one professional pharmacy organization, most commonly 


\section{American Journal of Pharmaceutical Education 2017; 81 (3) Article 52.}

Table 1. Student Characteristics and Leadership Experience $(\mathrm{N}=45)$

\begin{tabular}{|c|c|}
\hline Characteristic & n $(\%)$ \\
\hline Male & $15(33)$ \\
\hline Age, median (IQR) & $23(22-23)$ \\
\hline \multicolumn{2}{|l|}{ Grade point average $^{\mathrm{a}}$} \\
\hline$<2.5$ & $0(0)$ \\
\hline $2.6-3.0$ & $4(9)$ \\
\hline $3.1-3.5$ & $21(49)$ \\
\hline $3.6-4.0$ & $18(42)$ \\
\hline \multicolumn{2}{|l|}{ Pharmacy honors } \\
\hline Honors & $37(82)$ \\
\hline Honors society & $26(58)$ \\
\hline \multicolumn{2}{|l|}{ Work experience } \\
\hline Retail pharmacy & $35(78)$ \\
\hline Hospital pharmacy & $22(49)$ \\
\hline Other pharmacy & $6(13)$ \\
\hline Non-pharmacy & $9(20)$ \\
\hline \multicolumn{2}{|l|}{ Years of pharmacy work experience } \\
\hline$<1$ & $8(18)$ \\
\hline $1-2$ & $8(18)$ \\
\hline $2-4$ & $18(40)$ \\
\hline$>4$ & $11(24)$ \\
\hline \multicolumn{2}{|l|}{ Professional membership } \\
\hline Yes & $34(76)$ \\
\hline No & $11(24)$ \\
\hline \multicolumn{2}{|l|}{ Professional organizations ${ }^{b}$} \\
\hline American Pharmacists Association (APhA) & $24(71)$ \\
\hline Rho Chi Honor Society & $13(38)$ \\
\hline $\begin{array}{l}\text { New York State Council of Health-System } \\
\text { Pharmacists (NYSCHP) }\end{array}$ & $7(21)$ \\
\hline $\begin{array}{l}\text { American Society of Health-System } \\
\text { Pharmacists (ASHP) }\end{array}$ & $6(18)$ \\
\hline $\begin{array}{l}\text { American College of Clinical Pharmacy } \\
\text { (ACCP) }\end{array}$ & $5(15)$ \\
\hline $\begin{array}{l}\text { American Society of Consultant Pharmacists } \\
\text { (ASCP) }\end{array}$ & $5(15)$ \\
\hline Other & $4(12)$ \\
\hline \multicolumn{2}{|l|}{$\begin{array}{l}\text { Leadership positions held within professional } \\
\text { organizations }\end{array}$} \\
\hline President & $5(11)$ \\
\hline Vice President & $1(2)$ \\
\hline Treasurer & $2(4)$ \\
\hline Secretary & $2(4)$ \\
\hline Other & $4(9)$ \\
\hline
\end{tabular}

All values reported as $\mathrm{n}(\%)$ unless otherwise specified. IQR $=$ interquartile range. ${ }^{a} n=43 .{ }^{b} n=34$

American Pharmacists Association (71\%). Additionally, $27 \%$ of respondents held at least one leadership position within a professional pharmacy organization.

Thirty-nine $(87 \%)$ of the students who were enrolled in the study completed the second section of the survey pertaining to student satisfaction (Table 2). Over two-thirds of respondents reported that the longitudinal program exceeded their expectations. The remainder of the respondents indicated that the learning experience met their expectations (31\%). When asked if they would recommend the program to their peers, $85 \%$ responded that they would definitely recommend the program. Over $90 \%$ of respondents believed that the NYP-SJU program provided them with a better learning experience compared to completing rotations at five different institutions. When asked about strengths, 137 responses were received from the 39 respondents. Common responses included diversity of rotation experiences (37/137), preceptors (34/137), consistency of the practice site (30/137), and weekly student common hour (27/137). Collaboration with other health care professionals, networking, research, and publication opportunities were also considered strengths of the learning experience. Approximately $87 \%$ of respondents felt that the consistency in practice site allowed them to focus more on their rotations and $95 \%$ agreed that their rotations provided them with the opportunity to collaborate with other health care professionals. All respondents felt that the rotations facilitated critical evaluation of medications and development of interventions. When asked about weaknesses of the program, 24 weaknesses were identified from the 39 respondents; of note 23 respondents identified no weaknesses of the longitudinal program. The most common weakness identified was the availability of rotation experiences $(7 / 24)$, followed by workspace and computer availability (5/24) and preceptors (5/24). Finally, students enrolled in the longitudinal program reported that they were more likely to pursue a career in hospital pharmacy $(87 \%)$ and/or pursue a pharmacy practice residency $(87 \%)$ as a result of the NYP-SJU program.

Assuming an average of 8 hours for orientation, 8 hours for computer training, and 3 hours to become familiar with the institution, students gained approximately 76 hours of additional clinical experience compared to if they completed rotations at individual sites. Students attended 20 student common hours during the five block longitudinal experience. They presented a total of five case presentations and five journal club discussions. Those students who were enrolled in the program in 2012 and 2013 attended 10 student seminars. Seventeen $(38 \%)$ students completed a research project and presented their findings as a poster at a national conference. Additionally, 11 (24\%) students published a manuscript with an NYP preceptor.

Of the 45 students who completed the study, 30 $(67 \%)$ responded to the post-graduation follow-up survey. Two-thirds of post-graduation survey respondents pursued a pharmacy practice residency. Of the remaining post-graduation survey respondents, six accepted a job; four as a retail pharmacist, one as a hospital pharmacist 


\section{American Journal of Pharmaceutical Education 2017; 81 (3) Article 52.}

Table 2. Student Satisfaction With the NYP-SJU Longitudinal Program $(\mathrm{N}=39)$

\begin{tabular}{|c|c|}
\hline Measure of Satisfaction & n $(\%)$ \\
\hline \multicolumn{2}{|c|}{ Expectations of the NYP-SJU program } \\
\hline Exceeded & $27(69)$ \\
\hline Met & $12(31)$ \\
\hline Did not meet & $0(0)$ \\
\hline \multicolumn{2}{|c|}{ Recommend the NYP-SJU program to a peer } \\
\hline Definitely & $33(85)$ \\
\hline Possibly & $6(15)$ \\
\hline No & $0(0)$ \\
\hline \multicolumn{2}{|c|}{$\begin{array}{l}\text { Better learning experience with the NYP-SJU } \\
\text { program compared to rotations at five } \\
\text { different institutions }\end{array}$} \\
\hline Strongly agree & $26(67)$ \\
\hline Agree & $10(25)$ \\
\hline Neutral & $1(3)$ \\
\hline Disagree & $0(0)$ \\
\hline Strongly disagree & $2(5)$ \\
\hline \multicolumn{2}{|c|}{$\begin{array}{l}\text { Consistency allowed you to focus more on } \\
\text { rotations }\end{array}$} \\
\hline Strongly agree & $20(51)$ \\
\hline Agree & $14(36)$ \\
\hline Neutral & $4(10)$ \\
\hline Disagree & $0(0)$ \\
\hline Strongly disagree & $1(3)$ \\
\hline \multicolumn{2}{|c|}{ Collaboration with other health care professionals } \\
\hline Strongly agree & $27(69)$ \\
\hline Agree & $10(26)$ \\
\hline Neutral & $2(5)$ \\
\hline Disagree & $0(0)$ \\
\hline Strongly disagree & $0(0)$ \\
\hline \multicolumn{2}{|c|}{$\begin{array}{l}\text { Rotations at NYP allowed for critical evaluation } \\
\text { of medication therapy and development of } \\
\text { interventions }^{\mathrm{a}}\end{array}$} \\
\hline Strongly agree & $23(61)$ \\
\hline Agree & 15 (39) \\
\hline Neutral & $0(0)$ \\
\hline Disagree & $0(0)$ \\
\hline Strongly disagree & $0(0)$ \\
\hline
\end{tabular}

and one within research. Finally, one student entered into a master of public health program and one reported no job or additional training at the time of survey completion.

\section{DISCUSSION}

Students who were accepted into the NYP-SJU program were highly motivated as evidenced by their GPA, previous pharmacy work experience, receipt of honors in high school and/or pharmacy school, and leadership positions within professional pharmacy organizations. It is possible that student satisfaction with the NYP-SJU program and their success were directly related to the qualifications of the student rather than the training program. Despite this limitation, more than $90 \%$ of respondents believed that the NYP-SJU program provided them with a better learning experience compared to completing rotations at multiple other institutions. Students enrolled in the NYP-SJU program did complete rotations at other institutions and were therefore able to make a general comparison; however, the rotations were not identical in content, goals, or objectives, which limited the ability to make a direct comparison.

All students who participated in the NYP-SJU program had their expectations met with almost $90 \%$ of respondents agreeing that the consistency of the practice site allowed them to focus on rotations and deliver advanced patient care. Overall students gained approximately 76 hours of additional clinical experience by completing the longitudinal program. It is expected that during these hours, students were able to build their clinical knowledgebase through additional topic discussions, drug information questions, direct patient care, and completion of research projects. These results are similar to a recent publication in which the authors reported a net gain of rotation experience by eliminating hospital orientation for each new learning experience. ${ }^{4}$ Participation in the program also improved students' presentation skills through required case and journal club presentations. Finally, $38 \%$ of students conducted longitudinal research and $20 \%$ published a manuscript that they likely would not have been able to complete in a single rotation block.

A longitudinal rotation program may have a substantial impact on the trajectory of a student's career path. At the completion of the NYP-SJU program, the majority of students intended to pursue a pharmacy residency with $67 \%$ of the respondents going on to accept a pharmacy residency after graduation. Although the majority of respondents accepted a pharmacy residency, it is unknown whether this represents the majority of all students since only two-thirds responded to the follow-up survey. Without a comparator group of students who completed APPE rotations at multiple sites, we were unable to conclude whether the longitudinal program was directly responsible for the success of the students. Similarly, we were unable to determine the effect of rotations at other practice sites on the students' career paths. Additionally, it is expected that a longitudinal program would appeal to students who are interested in hospital pharmacy.

Longitudinal programs may better prepare students for a pharmacy residency by exposing them to current residents' activities, providing them with opportunities for presentation and research, and mentoring them on the application and interview process through the student seminar series. These distinct advantages may provide 


\section{American Journal of Pharmaceutical Education 2017; 81 (3) Article 52.}

students with a leading edge when applying for pharmacy residency programs, which have become increasingly more competitive. According to National Matching Service statistics for the American Society of Health System Pharmacists, in 2015, there were 4,358 participants in the post-graduate year one pharmacy residency match, of whom 1,547 (35\%) did not match. ${ }^{5}$ Although there are many advantages, completing rotations at the same site may decrease students' exposure to different patient populations, disease states, clinical practices, and policies and procedures. The NYP-SJU program is designed to prevent this limitation by requiring five rotations be completed at NYP, while the remainder of rotations are completed at alternate practice sites.

Limitations of the current study include self-reporting from students, subjective nature of questions, lack of a comparator group, and small sample size. Additionally, the response rate decreased with each section of the survey. Reporting of inaccurate information cannot be excluded; however, it is unlikely since the survey was administered after the program was completed. Additionally, the satisfaction section of the survey was anonymized.

\section{CONCLUSION}

Despite the barriers to scheduling high-quality APPEs, few hospitals have reported on the success of longitudinal rotation programs. ${ }^{3-4}$ The results of this study support the need for continual development of programs that engage students in APPEs that prepare them to deliver advanced patient care, while also providing them with opportunities for professional development.

The results of this study add to the body of literature surrounding student satisfaction with longitudinal APPE programs. This satisfaction most likely stems from the diversity of rotation experiences and preceptors, gain in rotation hours due to consistency of the practice site, opportunities for presentation, and the development of multidisciplinary relationships.

\section{REFERENCES}

1. Accreditation Council for Pharmacy Education. Accreditation standards and key elements for the professional program in pharmacy leading to the doctor of pharmacy degree. Standards 2016. https:// www.acpe-accredit.org/pdf/Standards2016FINAL.pdf. Accessed March 18, 2015.

2. Brackett PD, Byrd DC, Duke LJ, et al. Barriers to expanding advanced pharmacy practice experience site availability in an experiential education consortium. Am J Pharm Educ. 2009;73(5): Article 82.

3. Hatton RC, Weitzel KW. Complete-block scheduling for advanced pharmacy practice experience. Am J Health Syst Pharm. 2013;70(23):2144-2151

4. Taylor RA, Wisneski SS, Kaun MA, Parteleno P, Williams J, Goldman MP. Sequential advanced pharmacy practice experiences at one institution for students from three pharmacy schools. Am J Health Syst Pharm. 2014;71:140-144.

5. National Matching Services. Summary results of the match for positions beginning in 2015. https:/www.natmatch.com/ashprmp/ stats/2015applstats.html. Accessed January 11, 2016. 